\title{
La responsabilidad del niño que delinque
}

\author{
Osvaldo Agustín Marcón \\ Facultad de Humanidades de la Universidad Adventista del Plata \\ (UAP) - Entre Ríos, Argentina \\ Escuela de Trabajo Social - Santa Fe, Argentina
}

\section{La responsabilidad del niño que delinque}

Resumen: La discusión acerca de cómo el niño judicializado debe responder por los hechos delictivos cometidos genera dos posiciones dominantes. Desde una se exige una especial 'penalización' mientras que desde la otra se solicita 'responsabilización social y psicológica'. Este artículo discute ambas posturas en busca de una síntesis que tome lo mejor de ambas corrientes de pensamiento. Así, propone garantizar juicios justos coartando la tradicional discrecionalidad judicial en este campo pero, a la par, rechaza todo sistema de penas especiales como vía para la construcción de responsabilidad social y subjetiva. Inscribe esta alternativa en el campo de la Justicia Restaurativa a diferencia de los Sistemas de Responsabilidad Penal Juvenil. Propugna la noción de 'sanción co-responsabilizante’ antes que la de 'sanción responsabilizante', y la de 'garantismo integral' antes que la de 'garantismo penal'.

Palabras clave: responsabilidad, niñez, delito.

\section{A responsabilidade da criança que delinqüe}

Resumo: A discussão a respeito de como a criança judicializada deve responder pelos fatos delitivos cometidos gera duas posições dominantes. Uma delas exige uma especial 'penalização' entanto a outra solicita 'responsabilização social e psicológica'. Este artigo discute ambas as posições na procura de uma síntese que recupere o que há de melhor nessas correntes de pensamento. Assim, propõe garantir julgamentos justos, restringindo a tradicional discricionalidade judicial neste campo, mas, ao mesmo tempo, rejeita todo sistema de penalidades especiais como via para a construção de responsabilidade social e subjetiva. A alternativa proposta se insere no campo da Justiça Restaurativa, em oposição aos Sistemas de Responsabilidade Penal Juvenil. Defende a noção de 'sanção co-responsabilizante' em substituição do que se define como ‘sanção responsabilizante', e a de 'garantismo integral' em lugar da noção de 'garantismo penal'. Palavras-chave: responsabilidade, infância, delito.

\section{The Responsibility of the Delinquent Child}

Abstract: The discussion about how the prosecuted child should respond for criminal acts committed generates two dominant positions. One demands special 'punishments' while the other seeks 'social and psychological responsibilization'. This article discusses both positions in the search for a synthesis that maintains the best elements of each. It thus proposes to guarantee fair trials, restricting the traditional judicial discretion in this field, but simultaneously rejecting the entire system of special punishments as a route for the construction of social and subjective responsibility. The alternative proposed is inserted in the field of Restorative Justice, in opposition to the Systems of Juvenile Penal Responsibility. It defends the notion of 'co-responsibility sanction' to substitute that defined as 'responsibilization sanctions', and of integral 'guaranteeism' instead of the notion of 'penal guaranteeism'.

Key words: responsibility, childhood, crime. 


\section{Introducción}

La preocupación acerca de cómo intervenir ante la situación de los niños ${ }^{1}$ que cometen delito genera un significativo debate a nivel internacional. Más tarde o más temprano cada país deberá tomar posición a través de una institucionalidad específica. Tal nueva institucionalidad supone transformaciones ideológicas, políticas, metodológicas etc., aún allí donde supuestamente los sistemas han sido modernizados.

Este debate incluye una multiplicidad de dimensiones entre las que se destaca la cuestión de la 'responsabilización', entendida como urgencia por tratar al niño en tanto sujeto proporcionalmente necesitado de responder por el daño ocasionado. No se trata de un concepto más sino de un nudo central asociado a fundamentos filosóficos, ideológicos y políticos. Del perfil que la discusión adquiera en cada país dependerá el perfil de los sistemas operativos que se formulen o reformulen.

\section{Implicancias terminológicas}

El término 'responsabilidad' nos remite etimológicamente a la voz responsum, forma latina del verbo 'responder'. En principio podemos considerar, entonces, que 'responsabilidad' es la 'habilidad de responder'.

El Diccionario de la Real Academia Española (1996, p. 9978) prescribe diversas significaciones para el término. Destacamos aquí la idea de "responsabilidad" como "cualidad de responsable" pero señalemos que la obra alude también a la idea de "deuda, obligación de reparar y satisfacer, por sí o por otra persona, a consecuencia de un delito, de una culpa o de otra causa legal." La Real Academia Española también presenta como opción la "carga u obligación moral que resulta para alguien del posible yerro en caso o asunto determinado."

Vemos que la responsabilidad aparece recurrentemente como la habilidad de 'responder', término que admite como significaciones las siguientes:

Contestar, satisfacer a lo que se pregunta o propone; Contestar a quien le llama; Satisfacer el argumento, duda, dificultad o demanda; Replicar a los requerimientos o afirmaciones de otra persona; Rendir o fructificar; Corresponder con una acción a lo realizado por otra; Estar obligada u obligarse a la pena y resarcimiento correspondientes al daño causado o a la culpa cometida. (DICCIONARIO..., 1996, p. 9978).

Tenemos así, como mínimo, que la cuestión de la 'responsabilidad' funda una dimensión trascendente al individuo, participando de su constitución como sujeto-en-relación. Si bien incluye la necesidad de respuesta ante sí mismo, dicha capacidad de 'responder' está originariamente enclavada en la relación sujeto-contexto.

\section{Las oposiciones dominantes}

Ya se acepta que la 'responsabilización' es necesaria como vector que debe guiar la tarea con niños en conflicto con la ley penal. No obstante, como decíamos, al término se lo dota de diferencias significaciones. Siendo esquemáticos, podemos identificar dos tendencias dominantes.

En una de ellas se advierte la opción por la Responsabilidad Penal Juvenil. Consecuentemente, para administrar tal tipo de responsabilidad se piensa en diversas formas de Justicia Penal Juvenil. Aquí domina la lógica propia de la Justicia Penal adecuada a la niñez.

En la otra posición se opta por la responsabilidad social y psicológica al que le corresponde un tipo de administración conocido como Justicia Integradora (o Restaurativa). En sus formas más puras los componentes penales desaparecen.

\subsection{La Justicia Penal}

En gran parte de la bibliografía especializada podemos encontrar que la Responsabilización Penal es impulsada por EE.UU. en su condición de principal exportador de la 'penalización del conflicto social'. Este contexto es referenciado por Loïc Wacquant en Las cárceles de la miseria cuando describe el pasaje del Estado Providencia al Estado Penal, con la extensa serie de mecanismos que posibilitaron, según su opinión, la globalización de dicha tendencia.

Wacquant sostiene que:

Habría que reconstruir, eslabón por eslabón, la larga cadena de las instituciones, agentes y soportes discursivos (notas) de consejeros, informes de comisiones, misiones oficiales, debates parlamentarios, coloquios de expertos, libros académicos o para el gran público, conferencias de prensa, artículos de diarios y notas televisivas por la cual el 'nuevo sentido común penal' que apunta a criminalizar la miseria -y por esa vía, a normalizar el trabajo asalariado precario-, concebido en los Estados Unidos, se internacionaliza en formas más o menos modificadas e irreconocibles (a veces incluso por los mismos que las propagan), a semejanza de la ideología económica y social basada en el individualismo y la mercantilización, de la que es, en materia de 'justicia', la traducción y el complemento... el Estado no tiene que molestarse por las causas de la criminalidad de las clases pobres, al 
margen de su 'pobreza moral' (el nuevo concepto 'explicativo' de moda), sino únicamente por sus consecuencias, que debe sancionar con eficacia e intransigencia (WACQUANT, 2004, p. 22 y 50, subrayados del autor).

Podríamos agregar a los dichos de Wacquant que pareciera existir alguna correlación entre la impunidad en su sentido amplio (p.ej.: la debilidad del sistema penal ante el delito 'de cuello blanco') y esta tendencia mundial. Decimos esto porque no se trata, claro está, de un 'producto de exportación' que apunte a una distribución equitativa de las penas sino, por el contrario, de cierta forma de focalización penal sobre determinados sectores. En este marco de 'injusticia penal distributiva' se promueve la 'responsabilidad penal juvenil' como noción que, indefectiblemente, afianza la sobre-responsabilización del niño al momento de adoptar medidas judiciales. Tal exceso en la responsabilización (individual y sin contrapartida eficaz en el Estado) es identificado por Wacquant como 'meritocracia', es decir como un abuso del Estado al exigir al niño conductas que son difíciles de alcanzar o que, si las alcanza en las condiciones sociales impuestas, constituyen una nueva injusticia social. Más adelante volveremos sobre esta perspectiva crítica.

\subsection{La Justicia Integradora}

En cuanto a la segunda de las lógicas - Justicia Integradora - se sostiene que es impulsada con fuerza desde Europa. Al respecto destaquemos la significativa incidencia del dictamen del Comité Económico y Social Europeo (2006), dado en Bruselas el 15-03-06 bajo el título La prevención de la delincuencia juvenil, los modos de tratamiento y el papel de la Justicia del Menor en la Unión Europea. Dicho documento oficial analiza el problema en el contexto de la Unión Europea pero en él pueden detectarse numerosos puntos de coincidencia con la realidad latinoamericana.

Los europeos destacan como obstáculo la diversidad de posiciones existentes en sus países, contando entre ellas las posturas que tratan de ampliar el alicaído 'estado de bienestar' pero también las que eligen el mero endurecimiento en la intervención judicial, como por ejemplo la reforma introducida por los Países Bajos (1995) o Francia (1996). El dictamen evidencia preocupación pues encuentra en estas últimas cierta tendencia a la desresponsabilización del joven lo que, según entienden, debilitaría las posibilidades de transformación de sus conductas por la vía educativa.

No obstante el informe subraya cómo, a pesar de todo, la Unión Europea en su conjunto avanzó hacia lo que, precisamente, se conoce como 'modelo de responsabilidad'. Esta concepción refuerza la posición legal del joven garantizándole los mismos derechos y garantías que a los adultos, priorizando la prevención antes que la represión. A la par, insta a reducir al mínimo la utilización del servicio tradicional de Justicia ante estos casos y la maximización de la intervención a través de políticas sociales adecuadas promoviendo la utilización estrictamente excepcional de la privación de libertad ambulatoria. En esta línea de trabajo se incluye la amplificación y flexibilización de las medidas disponibles y, en concordancia, expone como condición sine qua non la especialización de todos los agentes que integran el servicio de justicia (jueces, empleados, policías, profesionales etc).

El documento europeo es muy claro al situar a estos jóvenes como parte de grupos 'en situación o en riesgo de exclusión social' considerando a la 'inserción laboral' como vía fundamental. En el orden de las causas subraya el predominio de los que denomina 'factores económicos y socioambientales' desglosándolos en: familias desestructuradas, marginación socioeconómica o pobreza, el fracaso escolar, el desempleo, los modelos violentos desde los medios de comunicación, el consumo de drogas, los trastornos de la personalidad y el comportamiento, los déficits en la formación cívica y la responsabilidad social.

\section{Las oposiciones en la República Argentina}

Ahora bien, la oposición que se expresa a nivel internacional tiene su versión local a través de distintos exponentes. Vamos a presentar solo dos de ellos, en este caso argentinos, por considerar que aportan nitidez a los efectos de trazar una imaginaria línea divisoria. No los proponemos como personalidades indiscutibles o portadoras de ideas indiscutidas en sus propios colectivos profesionales. Se trata, sí, de profesionales con larga trayectoria, instituidos como referentes nacionales e internacionales, por lo que sus dichos pasan usualmente a formar parte substancial en los debates académicos y/o profesionales.

\subsection{La posición a favor de lo penal en Argentina}

Emilio García Méndez viene sosteniendo, desde hace años, la necesidad de generar un 'sistema de responsabilidad penal' que sustituya el actual régimen adecuándose con ello, según opina, al marco normativo internacional y nacional. Como parte de sus argumentos suele insistir en que la mayor parte de los países latinoamericanos ya han avanzado en este sentido. Defiende, en concordancia con esta lógica, la sanción como medio socio-educativo habiendo acuñado para ello el concepto de 'sanción responsabilizante'. No repasaremos aquí la totalidad de sus desarrollos acerca de la cuestión penal juvenil 
pero sí trataremos de precisar aquellos que aluden a, precisamente, la posibilidad de utilización de la sanción con pretensiones educativas.

En el libro, García Méndez (2001, p. 192) sostiene:

La responsabilidad penal significa que a los adolescentes (de 12 a 18 años incompletos) se les atribuyen, en forma diferenciada respecto de los adultos, las consecuencias de sus hechos que siendo típicos, antijurídicos y culpables, significan la realización de algo denominado crimen, falta o contravención. Siendo las leyes penales el punto de referencia común para adultos y menores de 18 años, el concepto de responsabilidad difiere sustancialmente respecto del de imputabilidad en tres puntos fundamentales: a) los mecanismos procesales; b) el monto de las penas (adultos) difiere del monto de las medidas socioeducativas (adolescentes), y c) el lugar físico de cumplimiento de la medida.

Advertimos cuánta fuerza tiene en el pensamiento de García Méndez la idea de penalización siguiendo una vía que, teniendo formas diferentes a las previstas para los adultos, permita construir un camino substancialmente diferente (camino que identifica como 'mecanismos procesales'). Quizás aún más fuerte es la idea según la cual el tamaño de las medidas (expresada en el término 'monto') sería garantía de transformaciones subjetivas en el joven transgresor. Y aparece también la idea según la cual instituciones diferentes (o 'lugar fisico' en la cita presentada) completarían el triángulo conceptual transformador.

El autor sostiene, en el mismo pasaje del libro, que:

Un sistema de responsabilidad penal juvenil presupone la existencia de una gama de medidas socioeducativas que permitan dar respuestas diferenciadas según el tipo de infracción cometida. En general, esta escala incluye medidas tales como: a) advertencia; b) obligación de reparar el daño; c) prestación de servicios a la comunidad; d) libertad asistida; e) semi-libertad; y f) privación de libertad.

Observamos, nuevamente, la idea tan típica del razonamiento penal, aquí esbozada bajo el término 'escala'. Esta escala se articula a otro concepto no presentado a través de términos específicos pero que está evidentemente presente: la unilateralidad, entendida como la exclusión, desde el inicio del desarrollo teórico, de toda posibilidad de construcción conjunta de resarcimiento subjetivo. No sostenemos esto desde una posición ingenua: decimos 'construcción conjunta' dando por supuesta la existencia de un contexto obligatorio (el judicial) pero dentro del cual es posible procesar nuevos actos que resignifiquen lo actuado, es decir que permitan construir una nueva legalidad en articulación con la legalidad jurídica.

No obstante estos componentes, típicos del razonamiento penal, aparecen en la exposición de García Méndez (2004,p. 193) articulados a la noción de 'sanción responsabilizante', entendiendo inclusive que:

[...] un uso garantista y restringido de la medida socio-educativa de privación de libertad debería alterar radicalmente el panorama cuantitativo y cualitativo de las instituciones encargadas de la ejecución de esta medida... que requerirán métodos pedagógicos de tratamiento y medidas de seguridad que posiblemente no tienen precedentes en la región.

Al respecto recordemos que, en líneas generales, la moderna Pedagogía (ciencia por excelencia de la 'conducción del niño') tiende a reducir al máximo la utilización del castigo. No lo omite, pero lo ubica en un lugar radicalmente diferente del que ocupaba hace siglos atrás. No significa lo mismo disponer del castigo como un recurso más en una rica batería de posibilidades que colocarlo como primera opción en un sistema que no casualmente toma de él parte de su nombre: penal. Los niños que cursan procesos judiciales son tan niños como los que asisten a las instituciones escolares a menos que, sin decirlo, aceptemos remozar la vieja diferenciación entre 'niño y 'menor'.

\subsection{La posición a favor de la Justicia Integra- dora en Argentina}

Atilio Álvarez (apud MARCÓN, 2007) exhibe un historial profesional significativo en un campo de trabajo polémico que, como a Emilio García Méndez, le posibilitó tantas adhesiones como críticas ${ }^{2}$. Consultado en el marco de una investigación en la Maestría en Salud Mental de la Universidad Nacional de Entre Ríos calificó a la 'responsabilidad penal juvenil' como una concepción 'neo-retribucionista', es decir, como reaparición del postulado según el cual quien comete delito debe ser castigado "porque se lo merece' 3 y no porque se deba buscar un cambio en esa persona. 
En defensa de la Justicia Integradora (o Restaurativa) Álvarez sostuvo que:

La 'responsabilización' por el daño causado a la víctima y a la sociedad, y la actitud de reparación en lo posible de sus efectos, son esenciales al modelo de justicia restaurativa. Esa actitud es parte del proceso de crecimiento del chico... La irresponsabilidad nunca puede ser buena. Pero eso está en la antípoda de la 'responsabilidad penal juvenil' que proclama el discurso dominante. Desde mi punto de vista, la norma clave para abordar este tema es la regla cuarta de Beijing, con su amplio comentario contra la responsabilidad penal en edades tempranas. Justamente la exclusión de la responsabilidad penal - y por lo tanto del proceso penal en sí mismo respecto de los niños y adolescentes - es lo que permite avanzar en el tema de la responsabilización psicológica y social del joven y de su entorno. De lo contrario, lo que el neoretribucionismo de cuño anglosajón quiere tener es un joven delincuente arrepentido y confeso, en la más pura tradición de lo inquisitorial... En cambio, en un modelo restaurativo (yo prefiero llamarlo 'reparador' o el novedoso 'integrador') el tema de la responsabilización o de 'hacerse cargo' no pasa por lo penal, ni por la acción pública ejercida por el Fiscal. El Estado, inteligentemente, renuncia a ejercerla contra los niños. Y eso permite trabajar la responsabilidad personal ante la víctima... Es llegar a la conciencia de daño cometido por el joven, pero también a la conciencia sobre las deprivaciones causadas y sufridas por su familia y por su grupo social. Es avanzar sobre una asunción de responsabilidad mucho más amplia que la de la comisión del hecho. Jamás un sistema penal podría 'responsabilizar' a la familia y al grupo, ni integrarlos en el proceso penal. Por lo contrario, sí lo hace un modelo reparador o integrador. Este modelo se está haciendo entre muchos, no sin matices y diferencias propias de lo vital y naciente. Es un camino que comienza por la conciencia de fracaso y del fraude ideológico que significó el proceso neo-retribucionista impuesto en América Latina en las últimas décadas. Pero eso lo advierten en primer término aquellos que tiene mayor conciencia política... En toda Latinoamérica las personas que profundizan en política social están advirtiendo que lo que hemos vivido en Derecho de Menores en las últimas dos décadas fue una de las imposiciones del Consenso de Washington sobre lo social. Una aplanadora sobre la juventud excluida de América Latina. Y el problema de la responsabilidad personal es piedra de toque en la cuestión. No hay posibilidad de avanzar en ella sin admisión de la conducta y del grado de libertad de la misma, aun en el marco de pensamiento concreto del niño. Y esto es incompatible con el proceso penal, porque arroja por tierra toda noción de garantía trabajar desde el primer momento con la idea de 'hacerse cargo' de una conducta por la cual en la causa es y debe ser presunto inocente (ALVAREZ apud MARCÓN, 2007, p. 143 , subrayados del autor).

Se advierte cómo Álvarez inscribe la discusión en un marco político internacional específico. Atribuye la interpretación penal de los instrumentos internacionales a imposiciones externas identificando dos tendencias diferenciadas: Una "[...] que predican desde el Norte", según sus dichos, y otra a la que identifica como tendencia de cuño europeo. El autor citado inscribe la orientación dominante en el marco de los efectos políticos regionales del conocido Consenso de Washington, hito histórico al que diversos historiadores consideran como piedra fundacional del proceso neoliberal que caracterizó a la región durante las últimas décadas.

\section{La necesidad de una síntesis}

Expuestas las visiones elegidas por significativas, postulamos la necesidad de formular una síntesis que permita avanzar en términos de construcción de responsabilidades reconociendo al niño como sujeto de derechos. Ratificarlo en tal condi-ción es limitar el poder discrecional del que la Justicia dispuso sobre ellos durante aproximadamente un siglo. La revisión crítica de dicho siglo pone el énfasis en la fuerte tendencia a la 'judicialización de la pobreza', es decir, a iniciar procesos judiciales allí donde lo que evidentemente existen son situaciones de vulnerabilidad o exclusión social. La moderna doctrina reemplaza dicha fuerte tendencia por otra de la que se espera que la fortaleza sea orientada a atender la pobreza mediante políticas sociales. 
Ante la necesidad de buscar una repuesta, la lógica penal parece confiar en la ampliación del 'garantismo' al campo de la niñez. Pero el efecto inmediato de tal concepción es el tratamiento penal del problema pues, como se sabe, dicho 'garantismo' es 'garantismo penal'. Ahora bien: no se trata de oposición al diseño de un justo proceso en el que la vigilancia de las garantías constitucionales ocupe un lugar central. Se trata, por el contrario, de un proceso que 'garantice' la atención integral de los Derechos, limitando la mencionada discrecionalidad judicial. Dicho de otro modo, se trata de avanzar hacia formas de 'garantismo integral'.

Esto es materia de una discusión con fuerte impronta jurídica pero podríamos decir que se trata de un nodo conceptual contiguo al que, en realidad, nos ocupa en este artículo. Tratamos aquí de problematizar qué camino conviene seguir para que la construcción de responsabilidad no devenga en nueva injusticia derivada de la ya mencionada inequidad en la distribución de las penas. Por el contrario, tratamos de pensar formas de construcción de lo que, entonces, llamaremos 'co-responsabilización' antes que el asimétrico concepto de 'responsabilización'.

Para avanzar en tal tarea ¿qué categorías conceptuales convendría utilizar?

La ya citada investigación en la Universidad Nacional de Entre Ríos incluyó una consulta a Vicente de Paula Faleiros, trabajador social brasileño de gran relevancia intelectual. La entrevista se centró, precisamente, en la factibilidad de la 'responsabilización' en el niño que comete delito y, en particular, en las condiciones necesarias para que ella sea posible. Faleiros, en un tono coloquial pero no por ello exento de rigor, sostuvo:

\begin{abstract}
Me gusta mucho [...] la tesis de Piaget sobre heteronomía y autonomía, tomando responsabilidad como la capacidad de decidir las reglas para el conjunto de la sociedad, incluso para sí, con conciencia del todo. La heteronomía es el cumplimiento de las reglas para el otro, externo a sí mismo [...]. La reparación no es sólo un proceso objetivo de entrega de bienes, sino una educación de la libertad, una responsabilización en la construcción de una praxis fundada en el sujeto educando para que asuma críticamente el mundo, según la propuesta de Paulo Freire (MARCÓN, 2007, p. 150).
\end{abstract}

Advertimos en el pensamiento del autor que la búsqueda de autonomía involucra más voluntariamente al sujeto en la situación de la que forma parte, en tanto que la persistencia de la heteronomía promueve lo contrario, es decir, la dependencia de la intervención exterior. A fin de subrayar estos conceptos, encontramos que heteronomía y autonomía son dos estadios evolutivos que Piaget descubrió en el niño. Durante el primero la obediencia se lleva adelante porque es impuesta por un agente externo (el padre etc.). En el segundo la obediencia se lleva adelante pues se la reconoce como una construcción explícita o implícita pero conjunta (entre pares). En la obra Seis estudios de psicología, Piaget (1974, p. 76) informa de experiencias según las cuales niños aún heterónomos, al jugar, no discuten reglas recibidas externamente (de sus mayores) pero tampoco aceptan reglas inventadas por alguno de sus pares. Sostiene que:

Según ellos, en efecto, las únicas reglas son las que han utilizado siempre, las que utilizaban ya los hijos de Guillermo Tell o los hijos de Adán y Eva, y ninguna regla inventada ahora por un niño, incluso si esta regla es aceptada por las futuras generaciones, no sería realmente 'auténtica'. Es más, las 'auténticas reglas', que son, por lo tanto, eternas, no emanan de los niños: son los 'papás' o los ‘señores del municipio', los 'primeros hombres' o Dios, quienes han impuesto las reglas (en ello se percibe claramente hasta dónde puede llegar el respeto hacia las reglas transmitidas por los antepasados) (subrayados del autor).

Sin embargo, en grupos de edad mayor, ya en situación de autonomía, la reacción es distinta:

[...] la nueva regla puede pasar a ser 'auténtica' si cada uno de ellos la adopta, puesto que una nueva regla no es más que la expresión de una decisión común o de un acuerdo. Así es, afirma el niño, cómo se han constituido todas las reglas del juego, mediante una especie de contrato entre todos los jugadores. En este caso vemos cómo actúa el respeto mutuo: la regla es respetada no porque sea el producto de una voluntad exterior, sino como el resultado de un acuerdo, explícito o tácito. Y es por ello que es respetada durante la práctica del juego y no únicamente mediante fórmulas verbales: la regla obliga en la medida en que el propio yo la consiente, de forma autónoma, con respecto al acuerdo establecido. Esta es la razón por la que este respeto mutuo provoca toda una serie de sentimientos morales desconocidos hasta entonces: la honestidad entre los jugadores, que excluye la trampa, no ya porque esté 'prohibida' sino porque viola el acuerdo establecido entre individuos que se aprecian: la camaradería [...] (PIAGET, 1974, p. 77, subrayados del autor).

La referencia de Faleiros y los dichos del propio Jean Piaget cobran mayor significación cuando este último liga los conceptos de heteronomía y autonomía a lo que podríamos entender como estadios de maduración a nivel de conciencia moral, sin perder 
de vista que esto nos interesa desde la perspectiva de la responsabilidad. Así:

[...] desde este punto de vista se puede considerar esta moral de cooperación como una forma de equilibrio superior a la de la moral de simple sumisión. Ya hemos hablado, al referirnos a esta última, de sentimientos morales 'intuitivos'. La organización de los valores morales que caracteriza la segunda infancia es, por el contrario, comparable con la lógica propiamente dicha: se trata de una lógica de los valores o de las acciones entre individuos, al igual que la lógica es una especie de moral del pensamiento (PIAGET, 1974, p. 78, subrayados del autor).

Constante Kazuko Kamii, profesora en la Universidad de Alabama, trabajó en investigación bajo la dirección del propio Piaget. En su libro El niño reinventa la aritmética va más allá de este aspecto de la psicología infantil para precisar que:

La autonomía moral se refiere a la capacidad de realizar juicios morales y de tomar decisiones uno mismo, independientemente del sistema de recompensas, teniendo en cuenta los puntos de vista de las otras personas implicadas... Para las personas autónomas, las mentiras son malas independientemente del sistema de recompensas, de la autoridad de los adultos y de la posibilidad de ser descubiertas (KAMII, 1993, p. 50).

Kamii (1993, p. 50) sostiene que entre la heteronomía y la autonomía se da una relación evolutiva pero que en realidad:

[...] la mayoría de los adultos no se desarrolla de esta manera ideal. La gran mayoría detiene su desarrollo a un nivel bajo [...] Piaget (1948) indicó que es raro el adulto que llega a desarrollar una autonomía moral. Esta observación puede ser fácilmente confirmada en nuestra vida diaria. Los periódicos están llenos de historias de corrupción en el gobierno y de robos, violaciones y asesinatos.

Estas expresiones ponen en evidencia la magnitud del problema pues ya no pensamos en niños detenidos en la 'heteronomía' sino que, razonablemente, advertimos que dicho estado de desarrollo puede caracterizar a los propios operadores del sistema. Se trata de toda una estructura que tiende a aplicar 'penas' pues encuentra dificultades para pensarse a sí misma de un modo autónomo. Por ejemplo, las propias reglas de funcionamiento interno de los aparatos policiales, judiciales, penitenciarios etc., encuentran un fundamento central en la naturalización del castigo externo para corregir conductas. Expresiones populares tales como 'Somos hijos del rigor' ó 'Cuando nos vigilan nos portamos mejor' expresan con claridad tales limitaciones en materia de autonomía.

Volviendo a Kazuko Kamii (1993, p. 51), advertimos que desarrolla otro aspecto, fundamental en la discusión acerca de cómo el Sujeto avanza en términos de construcción de su capacidad de responsabilización, entendida ésta como dimensión substancialmente unida al desarrollo de la conciencia moral. La autora se pregunta, concretamente, lo siguiente:

¿Qué hace que algunos adultos sean moralmente autónomos? La pregunta crucial para padres y educadores es: ¿qué hace que algunos niños lleguen a ser adultos moralmente autónomos? Según Piaget, la respuesta a esta cuestión es que los adultos refuerzan la heteronomía natural de los niños mediante premios y castigos, y que estimulan el desarrollo de la autonomía cuando intercambian opiniones y puntos de vista con ellos. Cuando, por ejemplo, un niño dice una mentira, el adulto le puede dejar sin postre o hacerle escribir cincuenta veces: 'No volveré a decir mentiras'. El adulto también puede abstenerse de castigar al niño y, en cambio, mirarle a los ojos con gran escepticismo y afecto diciéndole: 'Realmente no puedo creerme lo que dices, porque [...]'. Las respuestas de este tipo invitan al niño a pensar $\mathrm{y}$ fomentan el intercambio de puntos de vista que contribuye al desarrollo de su autonomía. El niño que ve que el adulto no puede creerle puede verse motivado a pensar sobre qué debe hacer para ser creído. El niño que es educado con muchas oportunidades similares, con el tiempo puede construir por su cuenta la convicción de que, a la larga, es mejor que las personas mantengan un trato honrado y sincero entre sí (subrayados del autora).

Cerramos el punto 3.1 (La posición a favor de lo penal en Argentina) recordando algo obvio: el niño judicializado es tan niño como el que asiste a una institución escolar por lo que, entonces, la teoría jurídica no puede entrar en contradicción con la teoría pedagógica ampliamente validada. Siguiendo a la autora que venimos citando tenemos por inconveniente la utilización de cualquier sistema de 'penas' que, aunque especiales, pretendan ser aplicadas de un modo unilateral. Si además de unilaterales las mismas obedecen a una lógica 'tarifaria' (aumenta o disminuye la 'tarifa a pagar' según la naturaleza del acto protagonizado), podemos suponer que ellas se alejan significativamente de las posibilidades socioeducativas. Y subrayemos lo siguiente: es muy difícil que 'lo penal' pueda formar parte de una síntesis científicamente aceptable en el campo de la Teoría Social, del mismo modo en que tampoco puede formar parte de una síntesis científicamente aceptable en el campo de lo educativo (o pedagógico) y, menos 
aún, de la mixtura a la que se suele aludir con el término 'socioeducativo'.

En la misma obra (p. 51), Kazuko Kamii sostiene que:

[...] el castigo lleva a tres resultados posibles. El más común es el cálculo de riesgos. El niño castigado repetirá la misma acción, pero tratará de evitar que lo pesquen otra vez. Los adultos pueden decir: '¿Que no vuelva yo a pillarte haciéndolo otra vez!'. Algunas veces, el niño decide de antemano y estoicamente que incluso si lo descubren en un acto prohibido, valdrá la pena pagar este precio por el placer obtenido. La segunda posibilidad es el conformismo ciego. Algunos niños obedientes se convierten en perfectos conformistas, porque la conformidad les garantiza seguridad y respetabilidad. Cuando se vuelven conformistas del todo, los niños ya no han de tomar decisiones, pues todo lo que han de hacer es obedecer. La tercera consecuencia posible es la rebelión. Algunos niños pueden ser unos perfectos 'angelitos' durante años, pero llega un momento en que deciden que están hartos de complacer a sus padres y a sus maestros y que ya es hora de empezar a vivir por su cuenta. Incluso pueden llevar a cabo comportamientos característicos de la delincuencia. Aunque estos comportamientos pueden parecer actos autónomos, existe una gran diferencia entre autonomía y rebeldía. Normalmente, la rebeldía tiene sus raíces en la ira dirigida contra una represión, real o imaginaria. Las raíces de la autonomía son muy diferentes. El castigo refuerza la heteronomía del niño y le impide desarrollar su autonomía. Aunque los premios son más agradables que los castigos, también refuerzan la heteronomía del niño. Los niños que sólo ayudan a sus padres para obtener dinero y los que sólo estudian para obtener buenas notas, están gobernados por los demás, igual que los niños que son 'buenos' solo para evitar ser castigados. Los adultos ejercen poder sobre los niños mediante el uso de premios y castigos, y son estas sanciones lo que los mantiene obedientes y heterónomos (subrayados del autora).

En el campo de trabajo con sujetos en conflicto con la ley penal no es difícil encontrar expresadas las categorías de heteronomía propuestas por Kazuko Kamii. Si bien esto puede tomar diversas formas según las particularidades regionales, se advierten los efectos del actual sistema penal hegemónico. Así encontramos, por un lado, a aquellos transgresores que a sabiendas de que arriesgan - como mínimo su libertad ambulatoria deciden transgredir la norma penal establecida por considerar que el bien buscado lo vale. En dicho cálculo, claro está, el transgresor especula acerca de las deficiencias de los sistemas de control que pueden inclusive no llegar a sancionarlo (esto está desarrollado en la teoría criminológica).

También podemos identificar, sin demasiada dificultad, a aquellos que luego de ser atrapados por el sistema judicial represivo deciden soportar estoicamente las condiciones carcelarias. Aún las conocidas dimensiones degradantes de la privación de libertad son toleradas evitando todo reclamo. El supuesto básico es no desagradar a los operadores del sistema. Consignas tales como 'hacer conducta' sintetizan dicha actitud: soportar todo, a cualquier precio, hasta recuperar la libertad. Pero luego, fuera de la cárcel, esta actitud se prolonga soportando todo tipo de vejaciones sociales. La negación de toda posibilidad laboral, la estigmatización etc., son condiciones que prolongan el 'hacer conducta' por muchos años más e inclusive, en muchos casos, por el resto de la vida.

Pero desde luego que también es posible encontrar a aquellos que no realizan cálculos de riesgo pero tampoco, luego, 'hacen conducta'. Por el contrario, se afianzan en la línea de confrontación con la ley penal fuera y dentro del sistema carcelario. Aunque no excluyentemente, este tipo de posicionamientos se suele observar en situaciones de crisis carcelaria (motines), en nuevos delitos adentro de las cárceles, etc. Aquí advertimos la tercera opción presentada por la autora como producto de los sistemas que, por la vía de la sanción unilateral, pretenden alcanzar objetivos socio-educativos.

Ya desde una perspectiva más prospectiva Kazuko Kamii, en la misma obra (p. 51), profundiza su exposición sosteniendo que:

Si queremos que los niños desarrollen la moralidad de la autonomía, debemos reducir nuestro poder adulto absteniéndonos de usar premios y castigos, y alentarlos a que construyan por su cuenta sus propios valores morales. Por ejemplo, el niño sólo tiene la posibilidad de pensar en la importancia de la honradez si no se le castiga por decir mentiras y, en vez de ello, se le enfrenta con el hecho de que otras personas no pueden creerle o confiar en él. La esencia de la autonomía es que los niños lleguen a ser capaces de tomar decisiones por su cuenta. Autonomía no es lo mismo que libertad completa. Autonomía significa ser capaz de tener en cuenta los factores pertinentes al decidir cuál debe ser el mejor curso de acción a tomar. No puede haber ninguna moralidad cuando uno sólo se atiene a su punto de vista. Si uno tiene en cuenta los puntos de vista ajenos, no es libre de decir mentiras, romper compromisos o ser desconsiderado.

Esta es la zona conceptual a través de la cual podemos establecer el punto más cercano de contacto con la noción de responsabilidad social y psicológica, 
o bien con la idea de Justicia Restaurativa que hemos expuesto anteriormente. Es la posibilidad de concebir la 'responsabilización' como construcción conjunta y compleja. Se trata, dentro de un contexto obligatorio, de promover acciones que incluyan intermediaciones orientadas a responder por lo actuado - el delito - pero también a responder por lo no actuado - el déficit a nivel de políticas sociales. Se trata de concebir lo sucedido como unidad substancial de ambas dimensiones por lo que no es posible superar una sin, simultáneamente, actuar sobre la otra. La primera de ambas corresponde a la responsabilidad del niño y la segunda a la responsabilidad del orden público, representado por los organismos estatales específicos. La idea de 'sanción responsabilizante' podría, entonces, ser completada como 'sanción coresponsabilizante'.

Ahora bien, también sabemos que:

[...] Piaget era lo bastante realista como para decir que en la vida real es imposible evitar el castigo por completo. Las calles están llenas de coches, y evidentemente no podemos dejar que los niños toquen equipos estereofónicos o enchufes eléctricos. Sin embargo, Piaget realizó una importante distinción entre castigo y sanción por reciprocidad. Dejar a un niño sin postre porque ha dicho una mentira es un ejemplo de castigo, ya que la relación entre una mentira y el postre es completamente arbitraria. Decirle que no podemos creer lo que dice es un ejemplo de sanción por reciprocidad. Las sanciones por reciprocidad están directamente relacionadas con la acción que queremos eliminar y con el punto de vista del adulto, y tienen el efecto de motivar al niño a construir normas de conducta por su cuenta, mediante la coordinación de puntos de vista (KAMII, 1993, p. 50).

Lo expresado por la autora tiene relevancia en relación a la cuestión aquí tratada pues, hemos dicho, la noción de 'responsabilidad' adquiere diversas significaciones según el modo en que se operativiza. Conviene que toda medida judicial apunte a la responsabilización del niño lo que, entonces, también significa que aporte a la evolución desde la heteronomía a la autonomía. Siguiendo la línea esbozada por Kazuko Kamii (originada por Jean Piaget) tenemos que toda forma que exprese la lógica premio-castigo no es recomendable. Se requiere, por el contrario, y según lo expuesto, buscar formas que faciliten la articulación de perspectivas desde el propio Sujeto. Enseguida aclara que no se trata de un punto alcanzable sino del norte conveniente para guiar la construcción de los distintos sistemas.

En lo planteado aparece como categoría importante la diferenciación entre el mero 'castigo' y lo que la autora citada denomina 'sanción por reciprocidad'. Se entiende que el primero es propio de la etapa heterónoma y el segundo de la etapa en la que se aspira al mayor grado posible de autonomía, estado moral que puede considerarse óptimo como requisito para la construcción de ciudadanía.

En Estrategias de Empowerment en Trabajo Social el ya presentado Vicente de Paula Faleiros (1995, p. 62) trabaja sobre el concepto afirmando que:

Autonomía significa, al mismo tiempo, la capacidad de reproducirse en la complejidad de la historicidad y de la cotidianeidad de las mediaciones de poder, y de las energías y los recursos propios, y de representarse críticamente, combinando el refuerzo del yo con el aprendizaje de la duda (ENRIQUEZ, 1994), en el rechazo de la alienación, de la tutela, del control. Esta perspectiva se refiere tanto a lo colectivo como a lo individual [...] El desarrollo de la autonomía del sujeto implica la apropiación, por la conciencia, de la necesidad que está inscrita en la historia (BOURDIEU, 1992), y por el descubrimiento y el uso de la fuerza propia en el contexto en que se inscriben las necesidades y las posibilidades. En el campo de la solidaridad, las posibilidades de afecto y apoyo; en el campo de la cultura, las posibilidades de autoestima y expresión colectiva; en el campo de las instituciones, las posibilidades de garantía de derechos; en el campo de la economía, las posibilidades de capacitación, empleo y/o autogestión; en el campo de la organización, las posibilidades de autorregulación y resistencia al control, a la opresión, a la discriminación, a la victimización. El desarrollo de la autonomía es un proceso de negación de la tutela y de la subalternidad por la mediación de la afirmación de la palabra y de la construcción de las decisiones sobre el propio destino [...] En el proceso de autonomía de niños y adolescentes, es necesario desarrollar mediaciones de una relación de respeto hacia ellos, de estímulo su capacidad de reflexión y reacción frente a la correlación de fuerzas que les es desfavorable y que desemboca, habitualmente, en la violencia.

Aunque pensando originariamente en otro campo de aplicación, el pedagogo brasileño Paulo Freire (1995, p. 58) en Pedagogía de la autonomía ha llegado a sostener que:

El respeto a la autonomía y a la dignidad de cada uno es un imperativo ético y no un favor que podemos o no concedernos unos a los otros. Precisamente por éticos es por lo que podemos desacatar el rigor de la ética y llegar a su negación, por eso es imprescindible dejar claro que la posibilidad del desvío ético no puede recibir otra designación que la de ‘transgresión' (subrayados del autor). 
Freire coloca la cuestión de la autonomía, entonces, en un lugar paradojal pues la falta de consideración hacia ella es tomada como una 'transgresión', claro está que se refiere a una transgresión de orden ético y no a una transgresión de orden jurídico. Hemos planteado ya que una de las dificultades para avanzar hacia formas que promuevan la autonomía deviene de los propios sistemas judiciales y policiales. Son los propios operadores quienes razonan cotidianamente, y no solo frente al niño que comete delito, desde una perspectiva moralmente heterónoma. He ahí, entonces, una de los principales obstáculos a superar.

\section{Conclusiones}

El término 'responsabilización' está lejos de toda pretendida asepsia ideológica a partir de que, en cuanto tal, admite diversas interpretaciones. Algunas aparecen preocupadas por una concepción democrática con base en el 'garantismo penal', instalando dispositivos externos al sujeto (responsabilidad penal) aún cuando no pueda demostrarse claramente que por externos sean objetivos. Otras evidencian preocupación por la construcción de subjetividades propias de una institucionalidad genuinamente democrática (responsabilidad social) que profundicen el protagonismo integral del niño.

Esta bipolaridad está asociada a modelos internacionales con bases territoriales específicas y, entonces, a bloques geopolíticos precisos. Para el primero de los casos el liderazgo es reconocido en los Estados Unidos de Norteamérica, mientras que para el segundo el liderazgo es evidentemente europeo.

La formulación penal de la responsabilización queda indefectiblemente asociada al castigo unilateral y por ende asimétrico. Paradójicamente, pues se inscribe en un marco doctrinario que intenta negarlo, se asocia a cierta lógica paterno-filial según la cual el 'estado-papá' debe 'corregir-castigando' al 'ciudadano-niño'. Se filtra así una formulación que conserva algo de infantil transformando al castigo en un fetiche que puede, por sí solo, modificar conductas de un modo socialmente productivo. Exhibe inclusive cierto atraso científico al no tomar en consideración los avances que en otros campos disciplinares (p.ej.: la Psicología Genética o la Pedagogía, entre otras) han pasado a incrementar el patrimonio de la humanidad.

Los avances en materia de Derechos Humanos se deben, en gran medida, al Liberalismo Político. Pero con estos avances se ha producido un evidente contrabando ideológico que permitió el filtrado de décadas neoliberales a nivel latinoamericano. En el campo de las infancias la lógica penal exportada por Estados Unidos (y de gran acogida a nivel local), utiliza el 'garantismo' para arroparse ideológicamente como posicionamiento progresista. El 'garantismo penal' pareciera tomar, así, una dirección totalmente opuesta a la que le diera origen.

Claro está que estas cuestiones se advierten más en lo no dicho que en lo dicho. Desde luego que la ideología tutelar-represiva que reiterativamente denuncian diversos autores no es una ficción: existió y sigue existiendo. Pero pareciera recomendable reemplazarla por otra visión tan represiva como la anterior. Dentro de este escenario de lo no dicho pero operante aparece cierta dificultad para comprender el contexto político latinoamericano, opuesto claramente a la tendencia 'noventista' de perfil neoliberal.

Se advierte la necesidad de avanzar hacia una síntesis responsabilizante, democrática y - por ende no penal. Aludimos a lograr una concepción integralmente garantista y entonces co-responsabilizante. Subrayamos que dicho esfuerzo se verá obstaculizado, en primer lugar, por la propia moral heterónoma de los operadores del sistema. Las propias dificultades de policías, jueces, profesionales etc., para pensar autónomamente se constituye en el primer y más importante problema a superar, cuestión que no es posible solamente a través de nuevas leyes (jurídicas) sino a través de una nueva institucionalidad social (matrices de pensamiento, instituciones, leyes etc).

En definitiva, avanzar hacia formas de responsabilización social y psicológica, es decir hacia una justicia restaurativa, es entender que el hecho delictivo expresa la unidad substancial de dos transgresiones: la del niño que actúa transgrediendo la norma jurídica y la del Estado que no actúa eficazmente en términos de intervención a través de políticas sociales. Así devienen necesarias dos respuestas, también substancialmente unidas: la del niño, por su acto; y la del Estado por su no-acto. Este es el camino propuesto.

\section{Referencias}

COMITÉ ECONÓMICO Y SOCIAL EUROPEO. La prevención de la delincuencia juvenil, los modos de tratamiento y el papel de la Justicia del Menor en la Unión Europea. Al 01 dic. 2006. Disponible en: <http:// www.oijj.org.ar>. Acceso en: enero 2007.

DICCIONARIO DE LAREALACADEMIA ESPAÑOLA. Madrid: Espasa-Calpe, 1996. (Tomo 25).

FALEIROS, V. de P. Estrategias de Empowerment en Trabajo Social. Trad. de Pablo Bussetti. Buenos Aires: Lumen-Hvmanitas, 2003.

FREIRE, P. Pedagogía de la autonomía: saberes necesarios para la práctica educativa. Trad. de Guillermo Palacios. Buenos Aires: Siglo Veintiuno, 2005. 
GARCÍA MÉNDEZ, E. Infancia y adolescencia: De los derechos y la justicia. México, Unicef, 2001.

KAMII, K. C. El niño reinventa la aritmética: Implicaciones de la teoría de Piaget. Trad. de Genís Sánchez Barberán. Madrid: Visor, 1993.

MARCÓN, O. A. La explicación que realizan los sujetos que cumplieron Libertad Vigilada y/o Asistida respecto de la incidencia de la misma sobre su conducta posterior en relación con los hechos tipificados jurídicamente como delito. Tesis (Maestría en Salud Mental) - Universidad Nacional de Entre Ríos, 2007.

MARÍ, E. E. La problemática del castigo: el discurso de Jeremy Bentham y Michel Foucault. Buenos Aires: Hachette, 1983.

PIAGET, J. Seis estudios de psicología. Trad. de Jordi Marfa. Barcelona: Barral Editores, 1974.

WACQUANT, L. Las cárceles de la miseria. Trad. de Horacio Pons. Buenos Aires: Manantial, 2004.

\section{Notas}

1 Por razones metodológicas en este trabajo se utilizará el término 'niño' sin distinguir dicha categoría de otras tales como 'adolescente', 'joven' etc. Se elige tal denominación siguiendo lo prescripto por la Convención Internacional de los Derechos del Niño omitiendo el debate acerca de las limitaciones que el término supone.

2 Atilio Alvarez, jurista, titular de la Defensoría Pública de Menores de la Capital Federal, director de la carrera de posgrado de Especialización en Derecho de Familia de la Pontifica Universidad CatolicaArgentina(UCA).

3 Sobre 'retribucionismo' puede consultarse a Marí (1983)

\section{Osvaldo Agustín Marcón}

Especialista en Minoridad en la Facultad de Ciencias Jurídicas y Sociales de la Universidad Nacional del Litoral, Santa Fe, Argentina

Licenciado en Servicio Social y Psicopedagogo por las Universidades Nacional de Santiago del Estero y Católica de Santa Fe, Argentina

Docente en la Escuela de Servicio Social de la ciudad de Santa Fe e en la Facultad de Humanidades de la Universidad A. Del Plata, Argentina 